\title{
THE AgONIES OF COVID 19 ON VEgETABLE FARMERS ALONG THE WHITE VOLTA RIVER BASIN IN THE UPPER EAST REGION OF GHANA
}

\author{
Benjamin Bilalam Jabik \\ University of Energy and Natural Resources, Post Office Box 214, Sunyani, Ghana
}

\begin{abstract}
The emergence of COVID 19 coupled with the enforcement of its safety protocols, coincided with the peak of harvesting and saleof perishable vegetables in the 2020 dry season farming period in the Upper East Region of Ghana.Using a qualitative approach, this study investigates the effects of the pandemic on vegetable farmers along the White Volta River Basin in the Region. The findings are that there weredisrupted supply and demand in the production-consumption chain resulting in low sales; a shortage of hired labor; and high stigmatization. Farmers had few alternatives other than to leave their food stuff to rot on the farm, use the produce to feed livestock, or smuggleof the produce across borders. The implications are that the COVID 19 pandemic compounded the susceptibility of small-scale vegetable farmers in the region. Their resilience and household income levels are adversely affected.
\end{abstract}

\section{KEYWORDS}

COVID 19, safety protocols, vegetable farmers, resilience, food supply chain

\section{INTRODUCTION}

The novel coronavirus pandemic of 2019 (COVID 19) has so far been a threat to the global community. Since its outbreak, various countries adopted mitigation measures to reduce the transmission while the World Health Organization (WHO) declared the crisis as a pandemic, which might have conveyed a sense of urgency in managing the diseases. Across the globe, most of the mitigation measures adopted are designed to reduce the transmission of the virus by limiting physical contact between people. Unlike other infectious diseases where information on infection and mortality are used to estimate the loss in income, time and direct expenditure on affected people (Nuno, 2020), the coronavirus has spillover effects that are devastating. For instance, the effects of the safety protocols promoted in each country generate spillover effects throughout the supply chains and simultaneously disrupt both supply and demand (Nuno, 2020; Amewu etal., 2020). It also disrupts agricultural input and output systems thereby further affecting the future supply of agricultural produce. Other effects are observed in education, environment and public life.

The consumption of fresh fruits and green vegetable provides micronutrients like minerals and vitamins needed to maintain health and fight off infections as well as improve the immune system (Shiundu and Oniang'o, 2007), which is key for the fight against COVID 19. Vegetable farming has affected the way food is produced and processed as well as improve the welfare levels of those engaged in the supply chain (Ragasa and Lambrecht, 2020). Although vegetable production has contributed to improved wellbeing, its production and marketing are characterized by complex processes due to the perishable nature of the produce, high fluctuations in demand and supply, consumer concerns for food safety and quality, and dependence on climatic 
conditions (Negi and Anand, 2015). For instance, in the Upper East Region where this study has been conducted, the produce are seasonally grown by small scale farmers and the scale of production is clustered.

In recognition of the vulnerability of some agricultural produce, the government through the Minister of Agriculture exempted the agri-food system from domestic COVID-19 related restrictions on the30th March, 2020 (MoFA 2020). The release allowed (i) farmers to continue their farming activities; (ii) farm input dealers could continue distribution and sales of inputs; (iii) food processing companies could continue production and distribution of their products; and (iv) subsidized fertilizer and seed subsidies could continue to be provided through the Planting for Food and Jobs program. Despite this pronouncement, there existed reports of unavailability of food in some markets, instances of government security personnel restricting movements of traders of farm inputs and food despite their exempt status, and increased food losses in production areas and at markets due to supply chain challenges and low patronage (Amewu et. al., 2020).

The safety protocols developed and implemented to control the spread of the pandemic mainly focused on restricted movements and physical interaction of people (The Presidency, 2020; Amewu et al., 2020; Carreras et al., 2020). The safety protocols, although a control measure, had both direct and spillover effects on the wellbeing of people, including small-scale farmers in the country. Vegetable farming, commonly referred to as dry season gardening in the study area has become one of the effective ways of improving farmers' income levels and resilience in the Upper East Region of Ghana. However, with the outbreak of the COVID 19 pandemic in the region in 2020 coinciding with the peak of harvesting and selling period of the vegetables, this adversely affected farmers' livelihoods. Vegetable farmers are largely vulnerable due to the perishability of their produce, which is further aggravated by no storage and preservation facilities to preserve the produce. The paper is grouped into three main parts. The first part looks at the introduction and background of the paper, including literature review. The second and third sections cover the methodology of the study and the findings and discussions, respectively.

\section{OBJECTIVE OF THE STUDY}

This paper discusses the impact of the COVID 19 pandemic and the coping mechanisms adopted by green vegetable farmers along the White Volta Basin of the Upper East Region of Ghana. The objectives of the study is to:

- Establish the extent of the effect of the COVID 19 pandemic on vegetable farmers and,

- How the farmers are coping with those effects of the pandemic.

This is necessary because vegetable farming in the study area has become one of the approaches used to improve on farmers' income. Knowing the effect of the pandemic on vegetable farmers could be useful in taking decision that can help improve on the wellbeing of the farmers.

\section{Study ARea AND ReSEARCh Methodology}

This study was conducted among vegetable farmers along the White Volta River Basin that falls mainly within the Upper East Region of Ghana. Four communities, namely Kobore, Teogo, Toll Booth and Kpalugu, were selected for the study. This was so because these communities are among those that are predominantly engaged in dry season gardening activities along the river basin. The study communities are located in two districts - Bawku West (Kobore and Teogo) and Talensi (Toll Booth and Kpalugu). Vegetable production and marketing are paramount in these 
communities. The vegetables produced and marketed include tomatoes, onion, cabbage, garden eggs, pepper, water melon and yellow melon.

The White Volta Basin is one of the four major tributaries of the Volta River system. The White Volta River and its main tributaries take their sources in Burkina Faso, thereby making the management of the basin a trans-boundary activity (WRC, 2020). The water resources of the basin contribute substantially to the economic livelihood of the people in the study communities. Agriculture is the main economic activity in these communities and provides occupation and employment for a vast majority of the people. Some of the farmers in the communities engage in small scale irrigation schemes (mainly dry season), and farm along the river during the main farming season. Traditional farming practices such as slash and burn approaches are predominant, which results in degradation of both the land and water resources. The farming along the banks also results in the removal of the top soil, increasing the risk of siltation in the river through upland erosion and subsequent transport of sediment into the open water courses (WRC, 2008; WRC, 2020).

The research adopted an extensive qualitative approach to gather data for the study. Purposive sampling was adopted to sample vegetable farmers along the White Volta River Basin in the Upper East Region of Ghana. The criterion was that farmers who undertookdry season gardening along the White Volta River Basin were selected. A total of 108 vegetable farmers were interviewed. Extensive data gathering approaches such as focus group discussions (FGD), key informant interviews, observationand life histories were adopted to gather the data for the research. The selection of communities and individual respondents was rigorous and focused on communities along the river basin and farmers who are engaged in various vegetables farming.

To effectively implement the research, the sampling approach ensured that both male and female farmers were included as participants. To also avoid domination by some individuals, the focus groups discussion participants were segregated into female and male groups. The key informant interviews likewise interviewed both male and female individuals during the data gathering. In total, six key informants, three life histories, three site observations and eight focus groups provided data for the research. The FGDs had a minimum of ten participants and a maximum of thirteen participants. Females constituted almost one-third of the research participants. This was intentional so as to establish the gendered effect of the phenomenon on vegetable farmers. The data was collected within two weeks in October 2020.

\section{RESUltS AND DisCUSSION}

\subsection{Incidence of the Pandemic and the Safety Protocols in Ghana}

Ghana recorded its first case of COVID-19 infection on 12th March 2020 (GHS, 2020). By the end of September 2020, a total of 50,376 people were confirmed to have contracted the virus in the country. As the number of positive cases kept on rising, the Ghana government introduced various mitigating measures including promoting social distancing measures (stay at home, avoid handshake) and placing a ban on public gathering (ban on conferences, workshops, sporting and religious events, closure of bars, nightclubs and educational institutions); placing travel restrictions and border closures; promoting hand washing practices, mandatory wearing of face and nose masks; and eventually a three-week "partial" lockdown in Accra and Kumasi where the prevalence of the pandemic was escalating. The partial lockdown in the two metropolitan areas required all residents to remain at home except for transacting essential services like purchase of food, medicine, water or providing essential services like banking transactions, use of public toilet facilities, or medical care (The Presidency 2020; Amewu et al., 2020). The government 
started relaxing some of the social distancing measures at the beginning of June 2020, and by 1st September 2020, the airport was opened for international flights, with strict measures including mandatory testing at the point of entry. Although the study area was not included in the "partial" lockdown communities, it was adversely affected by the effects of the lockdown.

\subsection{Knowledge and Observation of COVID 19 Safety Protocols in the Study Communities}

With adequate knowledge on the pandemic and how to control the spread through the safety protocols contribute to controlling the spread of the virus and how to manage the pandemic. From the study it was realized that farmers along the White Volta River Basin in the Upper East Region have in-depth knowledge about the pandemic and the safety protocols that were promoted to help curb the spread of the disease. In all the eight FGDs and the six key informants interviewed, the participants demonstrated much awareness and knowledge about the disease and how it spreads among people when a question was posed on whether they were aware of the disease and its symptoms. According to the participants, sensitization about the disease and its mode of transmission was carried out on radios, television stations, community gatherings and individuals across the areas. The sensitization drive also covered the safety protocols that were promoted by the government. Politicians, religious bodies and individuals supported the communities with some safety hand washing equipment like veronica buckets, soap and tissue.

Out of the four communities visited, only two (Kpalugu and Toll Booth) indicated there were confirmed cases of the disease in a near-by community. These confirmed cases were imported into the community as patients were new police recruits who came to the police training depot for training. They revealed that although the confirmed cases were among police trainees and not their household members, it brought fear and panic into the communities due to the manner the disease spreads based on what they heard from the airwaves. The other communities in the Bawku West District revealed there were no confirmed cases around the area.

Although the farmers had adequate knowledge about the disease, the safety protocols were less observed during the time of the data collection. When the participants were asked why the safety protocols were less observed, mixed responses were presented. While about fifty per cent of the participants doubted the reality of the disease, about one third of the participants indicated the high temperature in the region and the perceived immunity of farmers make the disease less harmful. With a comparison to the cerebrospinal spinal meningitis (CSM) and malaria, which they have been experiencing annually with mortalities, about $75 \%$ of the farmers considered the disease less harmful.

\subsection{Infection and Mortality of COVID-19 in the Upper East Region}

As at the time of finalizing this paper, a total of 359 coronavirus cases had been confirmed, with six deaths recorded representing 1.67 percent of the reported cases in the region. This total of the confirmed cases in the region represents 0.7 percent of the 50,376 confirmed cases in the country. Although there are a number of confirmed cases in the region, there was no confirmed case among the study population. The mortality rate (six) in the region also represents 1.86 percent of the 323 reported deaths in the country (GHS, 2020). The statistics present a very worrying situation forthe region since, comparatively, itsmortality rate is higherthan that of the national mortality rate. These statistics, coupled with the belief and perception of immunity of farmers as presented by some of the participants, highlights the need for care to be taken to create more awareness about the disease. 


\subsection{Effects and Coping Strategies of the Farmers}

Although the prevalence of the disease at the time of the study as evidenced by the confirmed cases in the region was comparatively low and less than one percent of the total confirmed cases in Ghana, vegetable farmers along the White Volta River Basin in the region suffered severe consequence of the pandemic. Two of the study communities (Kpalugu and the Toll Booth) revealed there were imported cases of the disease in their areas.

The reaction of both the central and local governments, individuals, consumers and the media tomeasures to control the spread of the virus created simultaneous demand and supply effects on the farmers' produce. The restrictions that were imposed in April 2020, particularly the enforcement of social distancing and restricted movements as well as the partial lockdown of Accra and Kumasi (the major marketing centers of the green vegetables),greatly disrupted the supply chain. All the participants revealed that the social distancing and the restricted movement affected the movement of "the commodity queens" who are the major buyers of the vegetables in the region. The measures likewise affected movement of other customers and floating buyers of the produce who changed their consumption pattern. Since the produce are highly perishable, there were no otheravenues through whichto sell the produce. The disrupted chain and change in consumption pattern led to there being no available market for the produce in the region. Table 1 below presents some of the key safety protocols promoted by the government and how farming activities and families were affected in the communities. Table 1 has also provided the summary of coping mechanisms adopted by the farmers to minimize the effects on their livelihoods. The analyses revealed that the farmers adopted at least one coping strategy.

Table 1: Effects of the safety protocols and coping strategies on vegetable farmers

\begin{tabular}{|c|c|c|}
\hline Safety Protocol & Effect on vegetable farmers & Coping strategies adopted $(\% *)$ \\
\hline Restricted movement & $\begin{array}{l}\text { - } \quad \text { No market for the produce } \\
\text { (vegetables), } \\
-\quad \text { No labor to hire }\end{array}$ & $\begin{array}{ll}\text { - } & \text { Smuggled vegetables to } \\
\text { Burkina Faso }(45 \%), \\
\text { - }\end{array}$ \\
\hline Closure of schools & $\begin{array}{l}\text { No market for the } \\
\text { vegetables to schools, } \\
\text { - Increased food intake at } \\
\text { the household level }\end{array}$ & 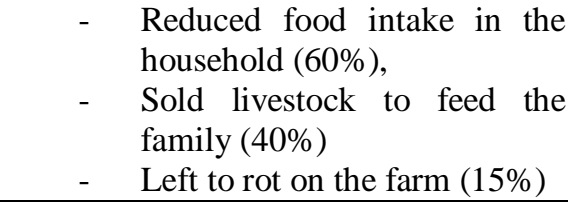 \\
\hline $\begin{array}{l}\text { Closure of hotels and } \\
\text { restaurants }\end{array}$ & No market for farm produce & $\begin{array}{ll}- & \text { Smuggled produce }(45 \%) \\
- & \text { Left to rot on farms }(15 \%) \\
\end{array}$ \\
\hline $\begin{array}{l}\text { Contact tracing and } \\
\text { quarantine }\end{array}$ & 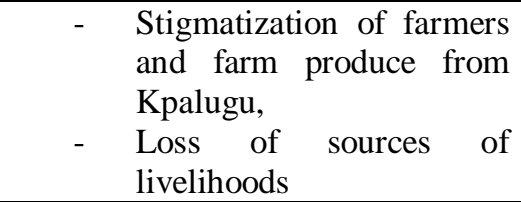 & $\begin{array}{ll}\text { Livelihood diversification } \\
(10 \%) \\
\text { - } \\
\text { Changing from vegetable } \\
\text { farming to food crops }(15 \%)\end{array}$ \\
\hline
\end{tabular}

*\% - Represents the proportion of the respondents adopting that coping strategy

As indicated (Table 1), effects of four of the safety protocols that were implemented by the central government and the local governments greatly affected both marketing and the production process of the vegetable farmers. The enforced restricted movement by the central government across the country as a measure to control the spread of COVID 19, which included banning of 
public gathering, conferences, closure of schools and partial lock down of Accra and Kumasi in April, disrupted the consumption and distribution chain of the produce. The enforcement of the restriction coincided with the peak of the sale of the dry season vegetables of the farmers in the area. The produce, which are mostly perishable green vegetables had no market since human movement, including the market women across locations, were affected by the restrictions. Although the transportation of food items were exempted from the restrictions, the middle women who are engaged in transporting the food items were not willing to move to the farms or productioncenters since the movement increases the risk of contracting the disease through the interaction of people along the distribution chain. Besides, the partial lockdown in the two major cities affected the demand of the produce and since vegetables are highly perishable, market women were not willing to purchase the produce since it could lead to them incurring losses. The law enforcement agencies were strict and insisted on evidence of exemptionalong the routes, which further increased the average time spent to get the items to the marketing centers; and since the vegetables are highly perishable, losses would occur. These factors discouraged the commodity queens from operating, which resulted in no market for the produce at the farm gates.

Another key effect of the restricted movement on the vegetable farmers was the shortage of hired labor during the pandemic, especially the vegetable farmers who depend on hired labor for their farm activities during the partial lockdown period. The restricted movement reduced labor supply and prevented laborers from moving from neighboring communities; and the few that were available within the farming communities became very expensive during the period. The farm laborersalong the river basin are mostly migrants from neighboring communities, who could not move to the farming areas for fear of either contracting the disease or being queried by the law enforcement agencies. One of the key informants in the study communities used the quote below to buttress his point:

\section{'We had no laborers to hire for farm work due to non-movement of laborers from the neighboring villages. The few we had was very expensive' (Key informant, 2020).}

To cope with these effects some of the strategies farmers adopted across the study communities included using the produce to feed their livestock; smuggling some of the produce to sell in Burkina Faso;leaving produce like tomatoes, water melon, cabbage and garden eggs to rot on the farms as little could be done to maintain their value; drying green pepper; and devoting much considerable time on the farm as there was no labor to hire to support in the farm work. The end result was the shutting down of some farm operations as farmers could not sell their outputs and thereby pay back the loans they secured to produce the vegetables. The effects and coping strategies were not different in the two study districts, except the smuggling of the farm produce to sell elsewhere.About $45 \%$ of the participants who were farmers in the Bawku West District smuggled some of the produce to neighboring Burkina Faso to sell. A key informant (a microcredit service provider to farmers) revealed some of his clients (green pepper farmers) smuggled their produce to Kumasi but could not get a market for the produce and had to transport them back for solar drying. This reduces the market value of the produce, and its purpose.An assessment of the effects on both the men and women showed there was no gender difference in the effects and coping approaches of the farmers in the two districts. Both men and women suffered the same consequences.

One other safety protocol that was promoted by the government was the closure of all schools across the country. As with the other safety protocols, the closure of schools affected demand for the produce since some of the schools served as the target market for the produce. Prior to the pandemic, the government school feeding program in the basic schools and the feeding of the students in the secondary school served as the major consumers of the green vegetables in the 
region. While there are no sale for the produce, feeding and demand for food at the household levels rather escalated since students who would have been fed at school were then to be fed at home. With no sales to support the additional mouths from schools, farmers resorted to selling livestock to feed the families as well as reducing the quantity of food intake at the household level. This implies that the enforcement of the safety protocols adversely affected household level food and nutrition security since there were more mouths to feed with no additional income at the household level.

Again, the demand for farm produce was negatively affected by the closure of hotels and restaurants. Hitherto, hotels and restaurants served as target markets for the green vegetables in the region. The closure of these public places affected the demand for the green products in the hotels, which directly translated to no market for the produce at the farm gates. The approaches adopted by farmers to cope with this situation were the same as the previous points, including using the green vegetables to feed their livestock, leaving it to rot on the farms, and donating to friends, amongst others.

One other severe effect of the enforcement of the protocols was stigmatization of farm produce and farmers. Farmers in the Kpalugu and Toll Booth communities suffered from public stigmatization due to contact tracing and quarantine of people who came into contact with COVID 19 infected people. During the outbreak of the pandemic in the region, some police recruits in Kpalugu police training school were tested positive of the virus. Due to the confirmation of the disease in the police training school, some relatives of some farmers were traced and quarantined. They had come in contact with the recruits through the sale of food items on the campus. As contact tracing, testing and quarantine of contacts, some individuals were affected. This further aggravated farmers' plight as the public stigmatized all people who came from Kpalugu to the neighboring communities. Floating customers such as travelers ceased patronizing the produce with the excuse that the sellers were potential carriers of the virus. Farmers who also tried selling their produce in Bolgatanga, the Regional Capital, could not avoid the stigmatization. In one of the FGD, a participant narrated her experience as captured in the quote below:

'Some of our produce like water melon, yellow melon, onion and green pepper are sold in the training depot as well as at the Toll Booth. Unfortunately, when the cases were confirmed at the depot, sales dropped drastically as sellers were contact traced and quarantined, floating buyers also cease buying at the Toll Booth and did not even want us to come closer to vehicles. As a result, our produce got rotten and some of the local middle women folded up their businesses' (FGD member 2020).

To cope with the stigmatization from the public, some farmers diversified their sources of livelihoods from vegetable farming to food crops farming, while others engaged themselves in the distribution chain. Although these were temporary measures, some farmers' plights worsened as they lost everything due to the unfavorable weather conditions and rainfall pattern in the area.

\section{CONClusion}

Coronavirus has disrupted and affected the livelihoods of vegetable farmers along the White Volta Basin in the Upper East Region of Ghana. Although, not much evidence of the disease is confirmed in the study communities, the spillover effects mainly from the safety protocols resulted in no market for the perishable crops leading to losses. The implication of the effects of the disease is that unlike other diseases where effect is easily measured by cost of treatment and time loss by patients, COVID 19 effects are more severe with the enforcement of the safety 
protocols thatcanaffect food and nutrition security issues at the household levels. The consequence of the effects may travel over years since productive capacities of farmers are hugely affected.

The consequence of the pandemic on farmers along the basin reflected signs of yet further hardship to manifest in their lives. This is because, while some of the farmers secured loans and farmed, they could not sell to pay back the loans. These loans are attracting higher interest but the farmers are left with no capital to help produce to enable them to pay back the loans. Moreover, although students were supposed to continue learning at home through television and other means as a result of the closure of schools, this affected students in the rural areas since many do not have access to the services. Rather, students capitalized on the non-availability of the services to move to their colleagues in the communities resulting in pregnancies and marriages. This can have a long term effect on the family since there will be more mouths feed within the household. In one of the study communities one of farmers indicated that a female student in their house became pregnant and got married, while a male student had impregnated a girl in another house.

\section{REFERENCES}

[1] Amewu S., Asante S., Pauw K. and Thurlow J. (2020): The Economic Costs of COVID 19 in Sub Saharan Africa: Insights from a Simulation Exercise for Ghana. The European Journal of Development Research https://doi.org/10.1057/s41287-020-00332-6

[2] Carreras M., Saha A. and Thompson J. (2020): Rapid Assessment of the Impact of Covid-19 on Food Systems and Rural Livelihoods in Sub-Saharan Africa. APRA COVID-19 Synthesis Report 1

[3] GHS (2020): Situation Update, COVID-19 outbreak in Ghana. https//www.ghanahealthservice.org/covid19/latest.php. Date accessed 18th November 2020

[4] MoFA. (2020). Press statement by Hon. Minister for Food and Agriculture on the Distribution andMarketing of food items during the period of restriction. Accra, Ghana: Ministry of Food and Agriculture (MoFA), Republic of Ghana.

[5] Negi S. and Anand N. (2015): Issues and challenges in the supply chain of fruits and vegetables sector in India: A review. International Journal of Managing Value and Supply Chains (IJMVSC) Vol. 6, No. 2, June 2015

[6] Ragasa C. and Lambrecht I. (2020): COVID-19 and the food system: setback or opportunity for gender equality? International Society for Plant Pathology and Springer Nature B.V. Food Security (2020) 12:877-880

[7] Shiundu K. M. and Oniang'o R. K. (2007): Marketing African Leafy Vegetables: Challenges and Opportunities in the Kenyan Context. AJFAND. Vol. 7 No 4.

[8] The Presidency (2020): Speeches. https://presidency.gov.gh/index.php/briefing-room/speeches Accessed 10 October 2020.

[9] WRC, (2008): White Volta River Basin - Integrated Water Resources Management Plan. Water Resource Commission, Ghana.

[10] WRC, (2020): Basins; White Volta River Basin. www.wrc-gh.org/basins/white-volta accessed 9th October, 2020 